International Journal of Pure and Applied Mathematics

Volume 102 No. $2 \quad 2015,225-231$

ISSN: 1311-8080 (printed version); ISSN: 1314-3395 (on-line version)

url: http://www.ijpam.eu

doi: http://dx.doi.org/10.12732/ijpam.v102i2.5

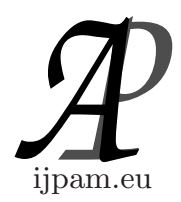

\title{
GRACEFUL LABELING OF EUCALYPTUS CLOUD CONNECTED IN A PATH
}

\author{
G. Sathiamoorthy ${ }^{1}$, T.N. Janakiraman ${ }^{2}$, N. Saravanan ${ }^{3}$ \\ ${ }^{1}$ Department of Mathematics \\ SASTRA University \\ INDIA \\ ${ }^{2}$ Department of Mathematics \\ N.I.T, Trichy, INDIA \\ ${ }^{3}$ School of Computing \\ SASTRA University, INDIA
}

\begin{abstract}
Cloud computing swears on divvying of resources to reach coherence and economies of exfoliation similar to a utility (like the electricity grid) over a network. Eucalyptus produces open source software for edifice AWS simpatico individual and loanblend clouds. A method for assigning IP address for each node of Eucalyptus cloud is proposed using graceful labeling algorithm. A graceful labeling of $\mathrm{n}$ copies of Eucalyptus cloud structure tree connected in a path $P_{n}$ is shown. It is proved that IP addresses generated by the proposed algorithm is unique in any network.
\end{abstract}

AMS Subject Classification: $05 \mathrm{C} 78$

Key Words: graceful labeling, IP address, eucalyptus cloud

\section{Introduction}

Cloud Computing is a well known technology same as internet and is anywhere.

Received: February 8, 2015

(c) 2015 Academic Publications, Ltd. url: www.acadpubl.eu 
It is a large scale infrastructure for hire. It helps the customers to access various resources from remote places on a self service basis. Any Cloud Computing environment will have the attributes like elasticity, pay by use, self service and programmable. The various services offered by any cloud computing environment are Software as a Service(SaaS), Platform as a Service(PaaS) and Hardware as a Service(HaaS). The use of cloud computing depends on various factors like fast response, the amount of storage, and the nature of the data like regulated or not. Any cloud environment will fall under three categories. They are (I) Compute Cloud (ii) Cloud Storage and (iii) Cloud Application. Compute Clouds will provide access to computing resources that are scalable and inexpensive to run the user code. Examples of Compute Clouds are Amazon EC2, Google App Engine etc. Cloud Storage is one of the ancient solutions of the Cloud Environment. It will be useful if data storage off site is preferred. Security and Cost are the primary issues of any cloud storage. Cloud Applications are based on software that use cloud infrastructure. It eliminates the need for installing and running application in the client's computer. Examples of Cloud Applications are torrent, Skype, etc., The major implementations of cloud are (I) Public (ii) Private (iii)Hybrid and (iv)Community. Public Cloud is one where a customer can find a location to run his/her application. It is implemented using thousands of servers over some hundreds of data centers across different locations. Private Clouds are used to organize the IT infrastructure of any organization. They use the best practices of the public cloud and are limited to some boundary. Hybrid clouds are a combination of both public and private clouds. Community clouds are set up when there are similar requirements. In this paper, the architecture of a private cloud is taken into discussion.

\subsection{Eucalyptus Architecture}

Eucalyptus is a web service based cloud infrastructure. The reasons for considering Eucalyptus in our discussion are: (i)It improves the understandability of cloud computing (ii) It acts as a test bed for using an actual cloud environment (iii) Ability to interact with public clouds and (iv) An open source software platform. Eucalyptus consists of four controllers namely cloud, cluster, storage ,node and a functional component Walrus. In this paper, a graceful labeling algorithm for labeling the nodes of an Eucalyptus architecture is proposed [5], [6]. The architecture of an Eucalyptus cloud taken in to discussion is given in Figure 1. 


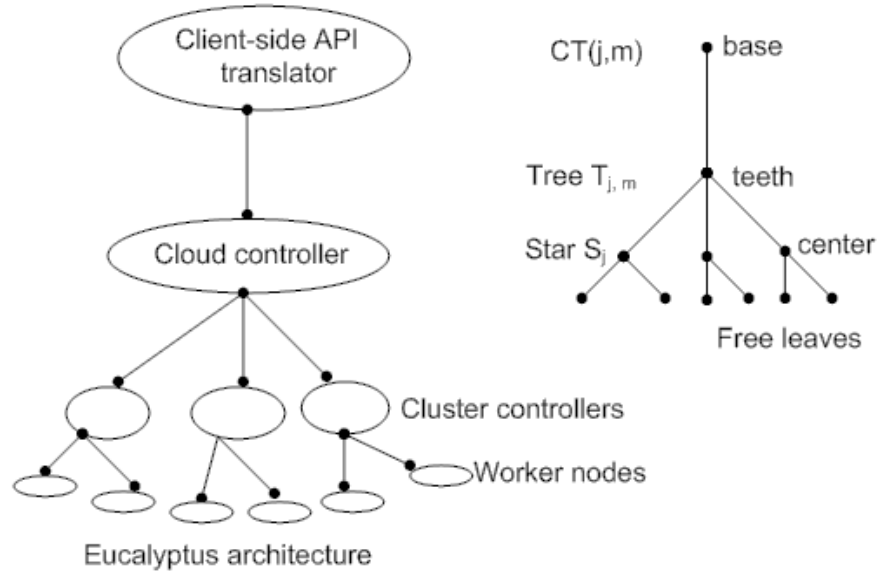

Figure 1: Eucalyptus architecture shown in above figure

\section{Graceful Labeling}

Graphs considered in this paper are simple finite and undirected. In general $G(V, E)$ denotes the graph $G$ with vertex set $V(G)$, edge set $E(G)$, such that $|V(G)|=$ p vertices $|E(G)|=$ q edges. A labeling of the vertices of $\mathrm{G}$ with the numbers from 0 to $\mathrm{q}$ is an injective map $\phi: V \rightarrow\{0,1, \ldots q\}$. A graph $\mathrm{G}$ is graceful if there exists a labeling of its vertices such that the map $\mathrm{g}: \mathrm{E} \rightarrow\{1,2, \ldots q\}$ given by $\mathrm{g}(\mathrm{uv})=|\phi(u)-\phi(v)|$, where $\mathrm{u}, \mathrm{v} \in \mathrm{V}$ and $\mathrm{uv} \in \mathrm{E}$ is a bijection.

A graph that admits graceful labeling is called graceful graph. The notation graceful labeling was introduced Rosa[2] with the name valuation.

Gallian [1]gives the extensive survey of contributions to graceful labeling of variety of graphs. The notation and terminology used in this paper are taken from[1]. There are many works relating to graceful labeling of trees, which are given in [1].[8], [7], [3], [4])

\section{Main Result}

Let $S_{1}, S_{2}, \ldots, S_{n}$ be n copies of a $\operatorname{star} K_{1, m}$. Merge one of the leaves of the stars $S_{1}, S_{2}, \ldots ., S_{j}$, which is called support points of all stars. Denote this tree as $T_{j, m}$ 2-level balanced tree. Let $T_{j, m}^{1}, T_{j, m}^{2}, \ldots, T_{j, m}^{n}$ be $\mathrm{n}$ copies of the 2-level tree $T_{j, m}$ and each copy is attached to teeth of the comb graph $P_{n} \odot L_{1}$. Let 
$t_{1}, t_{2}, \ldots, t_{n}$ be the central vertices of $\mathrm{n}$ copies of $T_{j, m}^{1}, T_{j, m}^{2}, \ldots, T_{j, m}^{n}$ respectively. The resulting graph is called cloud tree $(n, j, m)$. Here after we denote as CT(n, $\mathrm{j}, \mathrm{m})$.

Let the center points of $k^{\text {th }}$ star of $S_{k}$ be $\left(c_{1}^{k 1}, c_{2}^{k 2}, \ldots, c_{j}^{k j}\right)$ for $\mathrm{k}=1,2, \ldots, \mathrm{j}$. The free leaves of $k^{\text {th }}$ star of $S_{k}$ will be $(\mathrm{f}(\mathrm{k}, \mathrm{x}, 1), \mathrm{f}(\mathrm{k}, \mathrm{x}, 2), \ldots, \mathrm{f}(\mathrm{k}, \mathrm{x}, \mathrm{m}-1))$ for $\mathrm{k}=1,2, \ldots, \mathrm{j}$ and for $\mathrm{x}=1,2, \ldots, \mathrm{j}$. As each tree $T_{j, m}^{i}$ has its stars $S_{1}^{i}, S_{2}^{i}, \ldots, S_{j}^{i}$ with centers $\left(c_{1}^{i 1}, c_{2}^{i 2}, \ldots, c_{j}^{i j}\right)$. The edges of $T_{j, m}^{i}$ are denoted as $E\left(S_{i}\right)$ and the number of edges in $S_{i}$ are denoted as $\left|E\left(S_{i}\right)\right|=q_{i}$, for all i $=1,2, \ldots$, n. and $q_{i}$ $=\mathrm{jm}+1$. The total number of edges in $\mathrm{CT}(\mathrm{n}, \mathrm{j}, \mathrm{m})$ are denoted as $\mathrm{q}$ and $\mathrm{q}=$ $\sum_{r=1}^{r=n} q_{r}+(n-1)$.

The $\mathrm{CT}(\mathrm{n}, \mathrm{j}, \mathrm{m})$ contains either all $\mathrm{S}_{i}$ 's are isomorphic or $\mathrm{S}_{i}$ 's are even nondecreasing.

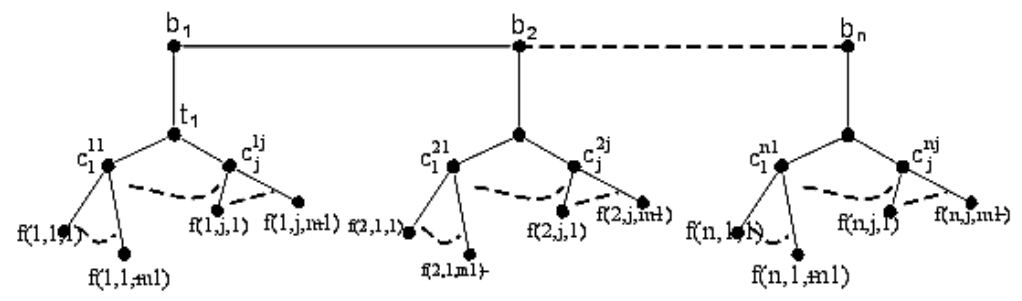

Figure 2: Eucalyptus cloud structure in the form of hanging rooted tree connected in a path

If we look at whole tree graph $\mathrm{CT}(\mathrm{n}, \mathrm{j}, \mathrm{m})$ graph it has three levels with 1. 0-level as path $\mathrm{P}_{n}$. 2. 1-level vertices which teeth of comb graph 3. 2-level vertices which are centers of the stars attached. 4. 3-level vertices which are free vertices attached to respective centers of the stars. Thus the given graph has 3-level of vertices. In this paper labeling of vertices are denoted by $\phi(\mathrm{v}) \cdot([6],[7])$

Theorem 1. $C T(n, j, m)$ is graceful.

Proof. The labeling of $\mathrm{CT}(1, \mathrm{j}, \mathrm{m})$ as follows.

$\mathrm{R}(1): \phi\left(\mathrm{b}_{1}\right)=0 ; \phi\left(\mathrm{t}_{1}\right)=\mathrm{q} ; \phi(\mathrm{c}(1, \mathrm{i}))=(\mathrm{i}-1) \mathrm{m}+1,1 \leq \mathrm{i} \leq \mathrm{n}$.

The free leaves of Star $\mathrm{S}_{1}$ as follows.

$\mathrm{R}(2): \quad \phi(1, \mathrm{k}, \mathrm{f})=\mathrm{q}-(\mathrm{k}-1) \mathrm{m}-\mathrm{f}, 1 \leq \mathrm{k} \leq \mathrm{j}, 1 \leq \mathrm{f} \leq \mathrm{m}-1$.

Now, the labeling of $\mathrm{CT}(2, \mathrm{j}, \mathrm{m})$ as follows.

$\mathrm{R}(3): \phi\left(\mathrm{b}_{2}\right)=\mathrm{q}-\mathrm{jm}-1 ; \phi\left(\mathrm{t}_{2}\right)=\mathrm{jm}+1 ; \phi(\mathrm{c}(2, \mathrm{i}))=\mathrm{q}-\mathrm{im}, 1 \leq \mathrm{i} \leq \mathrm{n}$. 
The free leaves of Star $\mathrm{S}_{2}$ as follows.

$\mathrm{R}(4): \quad \phi(2, \mathrm{k}, \mathrm{f}) .=(\mathrm{k}-1) \mathrm{m}+\mathrm{f}+1,1 \leq \mathrm{k} \leq \mathrm{j}, 1 \leq \mathrm{f} \leq \mathrm{m}-1$.

Now, we label $\mathrm{CT}(2 \mathrm{i}+1, \mathrm{j}, \mathrm{m}), 1 \leq \mathrm{i} \leq \mathrm{n}$ as follows.

$\mathrm{R}(5): \phi\left(\mathrm{b}_{2 i+1}\right)=\phi\left(\mathrm{b}_{2 i-1}\right)+\left|E\left(S_{2 i}\right)\right|+1,1 \leq \mathrm{i} \leq \mathrm{n}$.

$\mathrm{R}(6): \phi\left(\mathrm{t}_{2 i+1}\right)=\phi\left(\mathrm{t}_{2 i-1}\right)-\left|E\left(S_{2 i}\right)\right|-1,1 \leq \mathrm{i} \leq \mathrm{n}$.

$\mathrm{R}(7): \quad \phi(\mathrm{c}(2 \mathrm{i}+1,1))=\phi(\mathrm{c}(2 \mathrm{i}-1,1))+\left|E\left(S_{2 i}\right)\right|+1$.

The intermediate center vertices values are $\phi(\mathrm{c}(2 \mathrm{i}+1, \mathrm{k}))=\phi(\mathrm{c}(2 \mathrm{i}+1, \mathrm{k}-1))$

$+\mathrm{m}, 2 \leq \mathrm{k} \leq \mathrm{j}, 1 \leq \mathrm{i} \leq \mathrm{n}$.

The free leaves of Stars $\mathrm{S}_{2 i+1}$ are as follows.

$\mathrm{R}(8): \quad \phi(2 \mathrm{i}+1, \mathrm{k}, \mathrm{f})=\phi(2 \mathrm{i}-1, \mathrm{k}, \mathrm{f})-\left|E\left(S_{2 i}\right)\right|-1,1 \leq \mathrm{k} \leq \mathrm{j}, 1 \leq \mathrm{f} \leq \mathrm{m}-1$.

Now, we label $\mathrm{CT}(2 \mathrm{i}+1, \mathrm{j}, \mathrm{m}), 1 \leq \mathrm{i} \leq \mathrm{n}$ as follows.

$\mathrm{R}(9): \quad \phi\left(\mathrm{b}_{2 i+2}\right)=\phi\left(\mathrm{b}_{2 i}\right)-\left|E\left(S_{2 i+1}\right)\right|-1,1 \leq \mathrm{i} \leq \mathrm{n}$.

$\mathrm{R}(10): \phi\left(\mathrm{t}_{2 i+2}\right)=\phi\left(\mathrm{t}_{2 i}\right)+\left|E\left(S_{2 i+1}\right)\right|+1,1 \leq \mathrm{i} \leq \mathrm{n}$.

$\mathrm{R}(11): \quad \phi(\mathrm{c}(2 \mathrm{i}+2,1))=\phi(\mathrm{c}(2 \mathrm{i}, 1))-\left|E\left(S_{2 i+1}\right)\right|-1$.

The intermediate center vertices values are $\phi(\mathrm{c}(2 \mathrm{i}+2, \mathrm{k}))=\phi(\mathrm{c}(2 \mathrm{i}+2, \mathrm{k}-1))$

$-\mathrm{m}, 2 \leq \mathrm{k} \leq \mathrm{j}, 1 \leq \mathrm{i} \leq \mathrm{n}$.

The free leaves of Stars $\mathrm{S}_{2 i+2}$ are as follows.

$\mathrm{R}(12): \phi(2 \mathrm{i}+2, \mathrm{k}, \mathrm{f})=\phi(2 \mathrm{i}, \mathrm{k}, \mathrm{f})+\left|E\left(S_{2 i+1}\right)\right|+1,1 \leq \mathrm{k} \leq \mathrm{j}, 1 \leq \mathrm{f} \leq \mathrm{m}-1$.

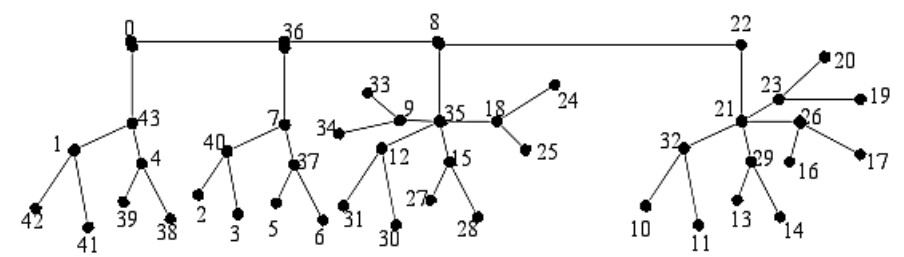

Figure 3: Example for $\mathrm{CT}(2,2,2)$ and $\mathrm{CT}(2,4,2)$ connected in a path, results $\mathrm{CT}(4,2$ and 4,2$)$

To prove the distinct edges of graceful labeling, the sum of Level (n-2) and Level ( $\mathrm{n}-1$ ) branches for $\mathrm{n}=2$ is always equal to $\mathrm{q}$. This result in cardinality between the levels is different. The center and free leave equals to q in leftmost branch and also the adjacent free leaves are either increase or decrease by 1 . This result in cardinality between center and all free leaves are different.

\section{Conclusion}

This results that the algorithm proposed for generating the IP address for the nodes of an Eucalyptus cloud tree forms a path $\mathrm{P}_{n}$ is graceful. The cluster 


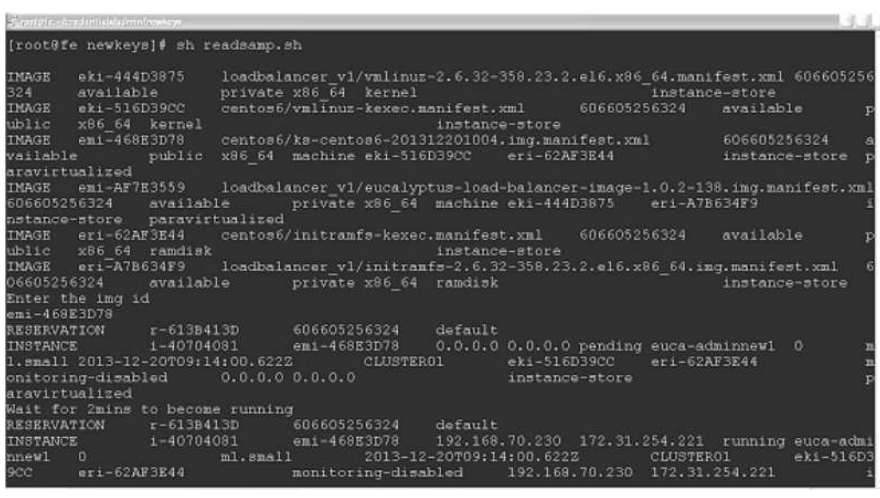

Figure 4: Input given in cloud data-1

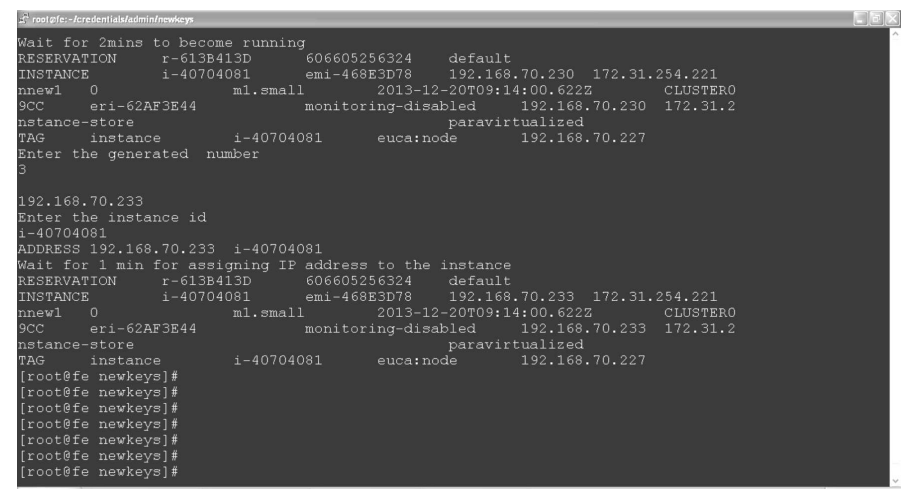

Figure 5: Output obtained in cloud data-2

controllers and worker nodes are increased as many as possible. Since it is graceful the IP addresses generated by the proposed algorithm is unique. It is also proved that the IP addresses generated for $n$ copies of the Eucalyptus cloud tree is unique and graceful.

\section{References}

[1] J.A. Gallian, A Dynamic Survey of Graceful Labeling, The Electronic Journal of Combinatories, fifteenth edition, (2012).

[2] C. Huang, A. Kotzig, and A. Rosa, Further results on tree labeling, Util. Math., 21c (1982), pp. $31-48$. 
[3] T.N. Janakiraman and G. Sathiamoorthy, Graceful labeling of a family of special tree with hanging stars having non-decreasing number of branches in random order, IJESACBT, vol 2, issue 3 (2011), pp. 130 - 138.

[4] T.N. Janakiraman and G. Sathiamoorthy, Graceful labeling of mobile nodes in a wireless network, Far East Journal of Mathematical sciences, Vol 66, issue 2(2012), pp. $265-276$.

[5] A. Mahendiran, N. Saravanan, N. Venkata Subramanian, N. Sairam, Implementation of $\mathrm{K}$-means clustering in cloud computing environment, RJASET, Volume 4, Issue 10 (2012), pp. 1391-1394.

[6] A. Mahendiran, N. Saravanan, N. Sairam, A review on leaders in cloud computing service providers and cloud SQL a case study, RJASET, Volume 4, Issue 17 (2012), pp. 2926 - 2933.

[7] Michelle Edwards and lea Howard, A survey of graceful trees, Atlantic journal of Mathematics, vol 1 (summer 2006), pp. 5 - 30.

[8] G. Sethuraman and J. Jesintha, A new class of graceful rooted trees, J. Disc. Math. Sci. Crypt., Vol 11 (2008), pp. $421-435$. 
